\title{
Educating Engineers about Product Design Methodology
}

\author{
Paul M. Kurowski \\ Department of Mechanical \& Materials \\ Engineering \\ Faculty of Engineering \\ The University of Western Ontario \\ pkurowski@eng.uwo.ca
}

\author{
George K. Knopf \\ Department of Mechanical \& Materials \\ Engineering \\ Faculty of Engineering \\ The University of Western Ontario \\ gknopf@eng.uwo.ca
}

\begin{abstract}
A successful product designer must combine natural creativity with the systematic use of structured design methodology and modern computer-aided design tools. Practice without proper instruction and formal guidance fails to recognize the vast knowledge of the design process developed by successful professionals. However, designing a product solely by theory without the experience derived from practice is ineffective because many subtleties and exceptions are learned by working on actual design project. In this paper, the authors discuss how formal lectures on product design and development methodology can be effectively combined with a hands-on design project leading to viable solutions by novice engineering students to open-ended problems.
\end{abstract}

\section{Introduction}

In recent years a heated debate has raged amongst instructors as to whether the goal of engineering design education is to engage students in loosely supervised projects or teach theory with established methodologies [5][8][9][11][12]. Taken to the extreme, both approaches to product design education will lead to unsatisfactory results. Practice without instructional guidance and formal structure fails to recognize the vast knowledge developed by design professionals over time and often leads to poor quality solutions. Similarly, designing products by theory without the experience derived from practice is ineffective because many subtleties and exceptions are learned by doing [4]. A successful designer must combine natural creativity with the systematic use of product design methods and tools [8].

Undergraduate students are abundantly creative and continuously amaze us with their inventiveness. Our challenge as University educators is not to make our students more creative but to show them how to use this creativity in a structured way to assure that their solutions satisfy real customer requirements and measurable engineering targets [8][11]. Engineering design is always customer-driven design with a clear need for the product or process. The goal of formal procedures and implementing proven methods is to provide the students with the means to document, justify, and communicate their design decisions. The course must both enhance the novice designer's creativity and ensure that the proposed design solution will lead to a high-quality, competitive product. These issues are introduced in the Mechanical and Materials Engineering at the University of Western Ontario in a compulsory second year course entitled Product Design and Development.

To emphasize the relationship between theory and practice his half-course combines extensive formal lectures on product design methodology with an intense hands-on product development project. The student's success in this course depends upon how well he or she can justify critical design decisions and demonstrate whether the proposed solution truly meets the customers' needs and requirements.

\section{Course in Product Design and Development}

The primary goal of the undergraduate course in Product Design and Development is to apply, analyze, and evaluate a variety of techniques that enable designers to develop high-quality products [8][12]. A quality product must meet the customer's requirements, perform to specifications, be cost effective, safe to operate, and have minimal negative impact on the environment during production, use or disposal. The formal design methods and the application of supporting tools [1][2][3][6][7][10] introduced in the lectures enable students to create the documentation and communicate key design decisions to the customer or client. 
Designing a "quality product" for function, cost and manufacturability involves a variety of tools and structured techniques ensuring that all elements of the product life-cycle from conception through to final disposal are systematically addressed by the engineer during the product design process. The role of the engineering design process in the product life-cycle is summarized in fgure 1. Although the act of doing design is restricted to the first three phases, critical design issues arise from all six phases of the product's life-cycle [11].

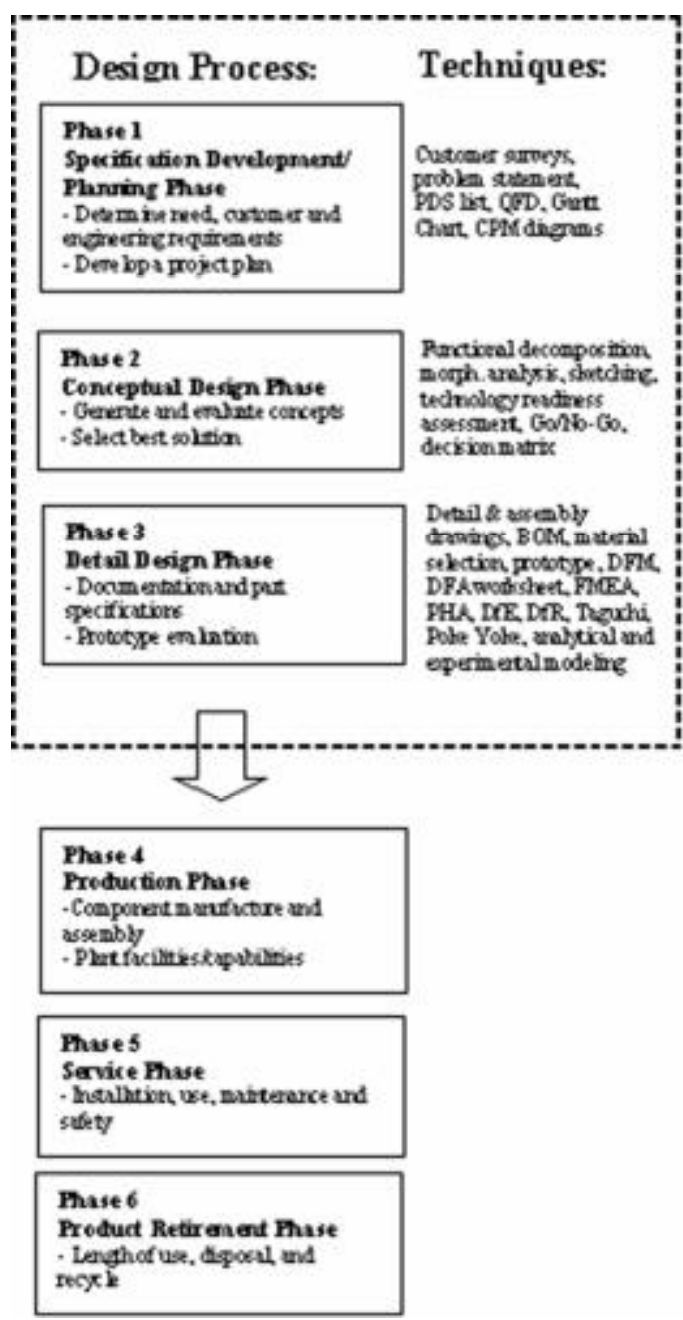

Figure 1. The six phases of a product's lifecycle and the role of the design process (dashed line box).

\subsection{Course topics}

The lectures in the second-year design course cover design philosophy, methodology, and general problem solving techniques. Students practice concurrent engineering design methodologies by implementing design techniques in a group project. Tutorial hours associated with the courses are used primarily for project planning, weekly assessment of design notebooks, periodic review meetings focusing on the product development file, and design team presentations. Considerable effort is spent on the design project outside the regular scheduled time. In addition, a formal timeline for deliverables is enforced in order to reinforce a professional work ethic.

The general topics covered by the course include understanding the customer, establishing measurable design specifications, preparing a realistic project plan, generating and evaluating concepts, developing the details for a viable solution, and demonstrating the effectiveness of the proposed solution. Techniques introduced in the lectures and utilized in the teambased project include Quality Function Deployment (QFD) [8][11][12], Gantt Charts, Critical Path Method (CPM), Functional Decomposition, Morphological Analysis, Decision Matrices, Design fr Reliability (DfR), Preliminary Hazard Analysis (PHA), Failure Modes and Effects Analysis (FMEA), Design for Assembly (DFA), Design for Disassembly, and Design for Environment (DfE) guidelines. Computeraided engineering tools such as CAD, FEA, and Motion Analysis are used to assist students in their product design. Issues related to surveying customers, product safety, risk assessment, and design for reliability are also investigated.

Upon successful completion of the course our students gain complete design experience: from identification of the need to prototype testing, all executed in a structured process where creativity is enhanced by the state-of-the-art product design techniques and methodologies. Each student is able to view product design as an open-ended problem solving activity and produces appropriate design documentation including maintaining a detailed individual notebook, Product Development File (PDF) and final product design report to be submitted to the client. Furthermore, the student understands issues of product safety, reliability and the principles of lifecycle engineering including re-manufacturing and design for zero waste. 


\subsection{Invited lecturers}

In addition to the lecture and design practice, several practicing engineers who are recognized leaders in their engineering disciplines are invited to speak to the students. The invited industry leaders talk openly about design challenges, ethical issues and social aspects of the practicing professional engineer. The presentations are very well received by the students and provide an important link to real world design challenges.

\section{Team-Based Design Project}

Students learn about the process of concurrent engineering design by developing a creative product for a specific customer's need. Each group is required to maintain a PDF which is a series of documents and appendices that cover the entire history of the design. When completed, the information stored in this file is used to draft a formal report that is presented to the client or sponsor of the project. The PDF represents an internal "company" record of the project whereas the formal design report is the end result that is delivered to the client.

In the context of the course the PDF and formal report are graded on completeness and quality of both the proposed design solution and the thorough documentation provided to support the design decisions. The approach taken by the team to solving the problem is emphasized more than the final proposed solution.

\subsection{Project theme}

The primary goal of design project is to critically apply the product design techniques introduced in lectures. This is achieved if the participants are given a properly defined project. The students must be able to relate to the project theme and identify potential customers for the product. Since the objective is customer-driven design, it is also essential that the students have access to potential end-users in order to develop realistic customer requirements and provide knowledgeable individuals to critically evaluate the proposed solution. In this manner it is the customer, and not the engineering student, who identifies "what is truly needed" and whether the "solution is useful". Over the past decade, the design projects associated with this course involved products assisted individuals with limited physical abilities.

The initial part of the design process requires the team to select a specific client group and identify a need. A past example is an assistive device that would enable a person with severe arthritis in the hands to undertake recreational painting. Another design team would explore another recreational activity, such as sport fishing, enjoyed by the same client group. In all cases the team must consult potential end-users of the product to identify the activity or task requiring assistance, and demonstrate that specifications were developed from their needs.

Additional constraints placed on the design solution ensured that the proposed product must be safe, affordable, simple to use and easy to maintain. The estimated cost of manufacturing the final product must be less than $\$ 20$. This is based on the rule-of-thumb that the estimated retail price for a consumer product is often $3 x$ the manufacturing cost.

\subsection{Forming the design teams}

Two approaches have been used in creating the four member design teams. The first approach is to assign students into groups with the goal of increasing the diversity and backgrounds of the teams. The second approach is to permit students to select there own design team members. Both approaches have advantages and disadvantages.

By assigning students to teams it is possible to enhance concurrent engineering practice. Concurrent engineering is only effective if the participants in the group have different backgrounds, perspectives, and areas of expertise. Unfortunately, this group dynamic may result in serious internal conflicts amongst novice, overly confident designers. On occasion this behavior can result in complete breakdown of the functioning of the group. In contrast, a self forming team reduces this risk of internal conflict but significantly increases the chances that the team will develop a preconceived "favorite" solution without thoroughly understanding the problem. The final decision of which approach to use is also dependent upon the course instructor's preference.

\subsection{Monitoring progress}

During the twelve week duration of the design project, students are required to keep the log of all activities in individual design notebooks. As a team, they are required to report progress in several design reviews and in the final presentation. Each team must submit the final report along with all the relevant project documentation that they have collected in a Project Design File. 
A design review meeting is be held at the end of each of three design phases, or more often if deemed necessary. At each meeting the design team provides a short presentation that clearly states the design problem, progress made, and problems encountered. In addition, a detailed plan for the next phase of work must be presented at this meeting.

Enforcing this structured design process where students are required to go through clearly defined design phases is perhaps the biggest challenge for the course instructor. It is authors' experience that many students initially see this as an unnecessary constraint to their creativity. Many teams try to bypass the initial design stages like identification of need, development of product specifications, generation of multiple concepts and concept selection. Instead, they try to start the project with a pre-conceived idea using an intuitive approach to design process which does not assure that customer need will be satisfied and a competitive product will be created.

\subsection{Evaluating individual performance}

Each student keeps a hard-cover design notebook describing their individual contributions to the design project. This includes all sketches, notes, experimental data, design ideas, and record of communication with team members, clients and potential vendors. No pages can be removed and each page must be dated and initialized when used. At the beginning of each laboratory period, the prior week's entries in the design notebook are be evaluated by the course instructor or a teaching assistant. The design notebooks are collected at the end of the term and assigned a grade based on both the weekly assessments and the final number of "quality entries". A quality entry is a significant sketch or drawing of some aspect of the design; a listing of functions, ideas, or other features; a table such as morphology chart or decision matrix; or a page of text.

Furthermore, each team receives a grade for the PDF, design report and prototype. The mark assigned to an individual is adjusted based on feedback from all team participants. In this regard, students are required to submit a questionnaire that describes their own contribution to the team effort and that by the other members of the group. The individual contribution is then calculated using all evaluations forms and the observations of the instructor and teaching assistants. This process provides the students with a mechanism to have a voice in the grading process. Historically, the majority in a group provide the same observations identifying those individuals who made greater or lesser contributions.

\section{Design Solution - A Case Study}

Each year the students are divided into approximately 25 design teams of four to work on design solutions for some kind of assistive devices that satisfy he specialized needs of disabled or elderly individuals. The teams that satisfactorily follow the product design and development process often generate relevant, innovative product solutions.

The goal of a sample project we present here is to "design a device that helps seniors make an easy transition from sitting to standing". We will follow the team through their design projects. Of course, only a limited number of details of this representative project can be shown in here.

The team begins with interviews with potential end users of the product and identifies the need for a device that would assist in standing up and sitting down. The most important customer requirements are listed and assigned a rating of importance through further interviews (figure 2). Competitive products already available on the market are also identified and rated based on the es tablished customer requirements.

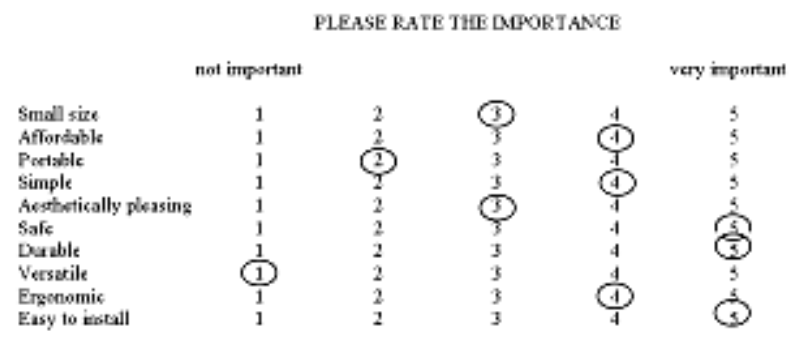

Figure 2. A sample response to a survey used
to identify key customer preferences.

Next, the Quality Function Deployment (QFD) technique (figure 3 ) is used to develop design specifications and to compare them with design specifications of the existing competitive products. 


\section{QFD - Quality Function Deployment}

\begin{tabular}{|c|c|c|c|c|c|c|}
\hline & & Weight & Length & Width & Volume & $=1$ \\
\hline Small She & J) & 4 & 9 & 9 & 9 & \\
\hline Aitcrdable. & 4) & 1 & & & & \\
\hline Portable & 4 & 9 & & & 9 & \\
\hline \multicolumn{7}{|l|}{ Simple } \\
\hline \multicolumn{7}{|l|}{ Aasthetics } \\
\hline \multicolumn{7}{|l|}{ Sale } \\
\hline \multicolumn{7}{|l|}{ Durable } \\
\hline \multicolumn{7}{|l|}{ Versotile } \\
\hline \multicolumn{7}{|l|}{ Ergonomic } \\
\hline \multirow{2}{*}{$\begin{array}{l}\text { Easy Installation } \\
\text { Adequate Speed }\end{array}$} & $d$ & 4 & & & & \\
\hline & 3 & 1 & & & & \\
\hline Ahapliste inportance & 498 & 71 & 27 & 27 & 53 & \\
\hline \multirow[t]{2}{*}{ Relative importance } & & $14 \%$ & $5 \%$ & 59 & $13 \%$ & \\
\hline & & $\mathrm{kg}$ & $m$ & $m$ & $m^{2}$ & \\
\hline
\end{tabular}

Figure 3. Portion of the QFD chart showing development of design specifications.

The identification of customer requirements by means of customer surveys and translating them into engineering requirements using the QFD techniques ensures that design process is customer driven. Once the design specification and engineering targets have been established the team moves forward to the concept generation and concept evaluation phase.

Techniques such as Functional Decomposition and Morphological Analysis (figure 4) are used to develop innovative solutions. In our case, the design team makes use of these two techniques to produce over ten design concepts. Sketches for only two of these concepts are shown here (figures 5 and 6).

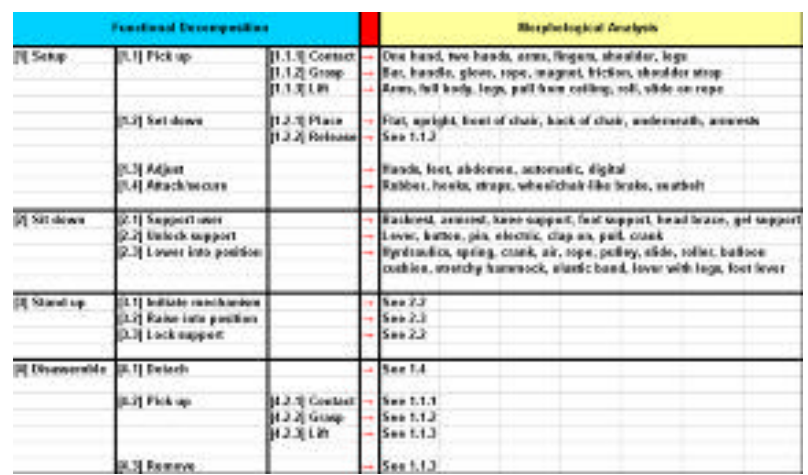

Figure 4. Example of concepts being developed through functional decomposition and morphological analysis

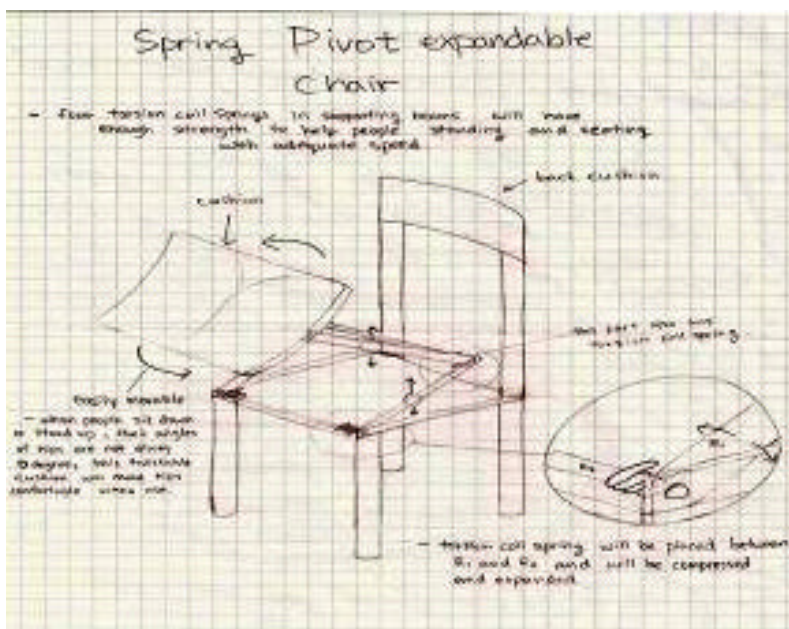

Figure 5. Design concept 1: chair with spring loaded seat.

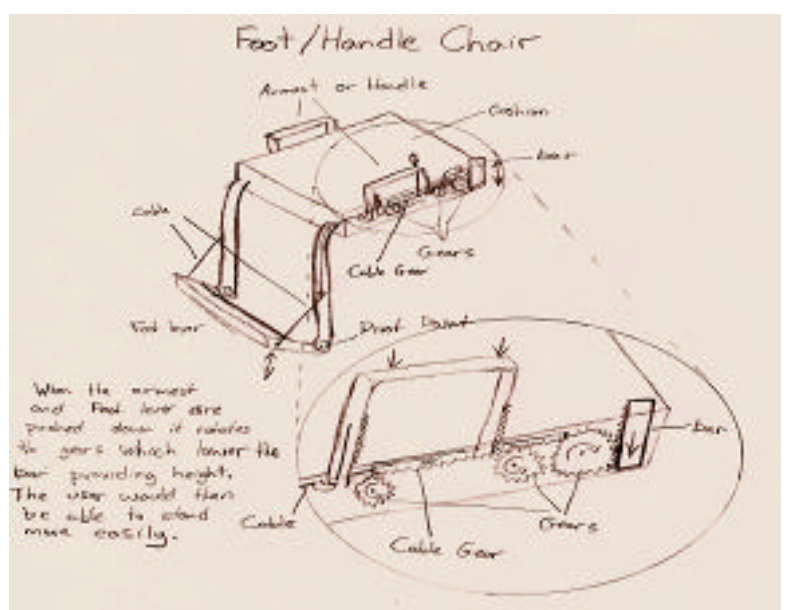

Figure 6. Design concept 2: chair with foot step and handles.

Having developed design concepts, concept evaluation techniques including Feasibility Judgment, Technology Readiness Assessment, Go/no-go Screening and Decision Matrix Method are used to select the best concept for detail development.

Go/no-go Screening technique (figure 7), combined with Decision Matrix Method indicates that Spring Compressive Chair is the most promising design concept.. 


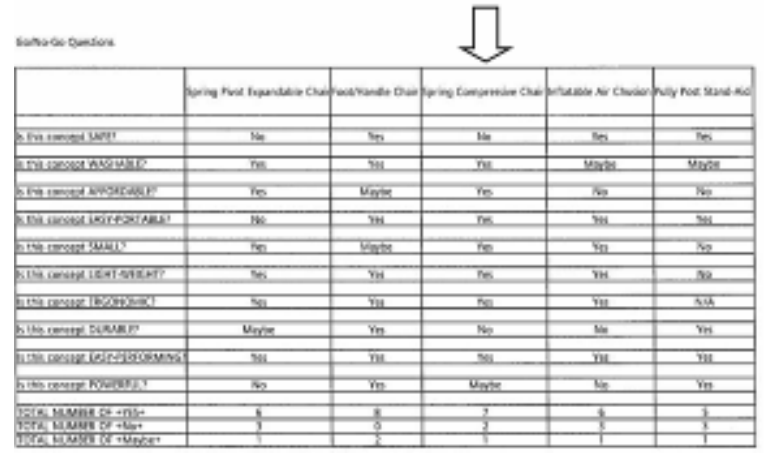

Figure 7. Go/no-go technique used to select the best design concept for detail development.

This selected concept must now be developed into a viable functional product through engineering analysis, mechanical prototyping, experimentation, and evaluation for manufacturability, safety, reliability and impact on the environment. Example of the CAD model for the assembly and Bill of Materials (BOM) are shown in Figures 8 and 9, respectively.

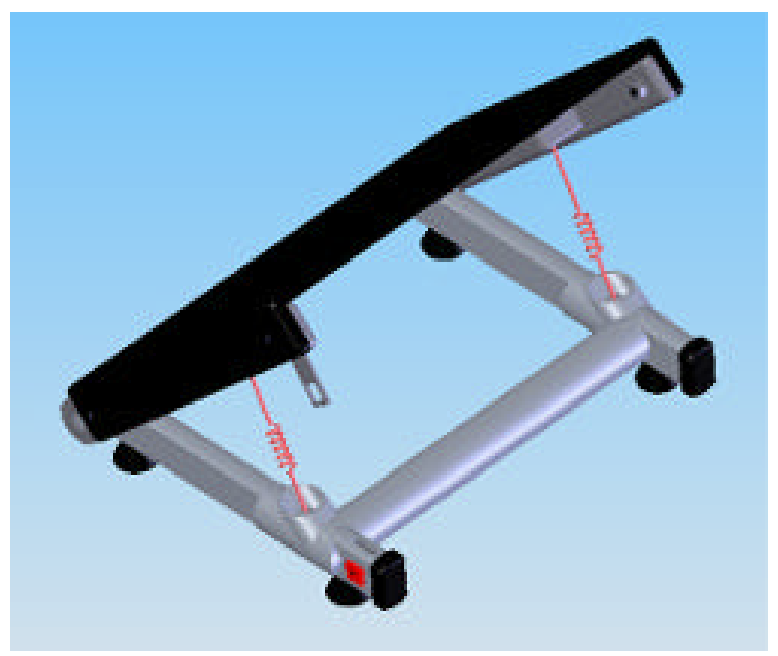

Figure 8. CAD model of a spring loaded seat.

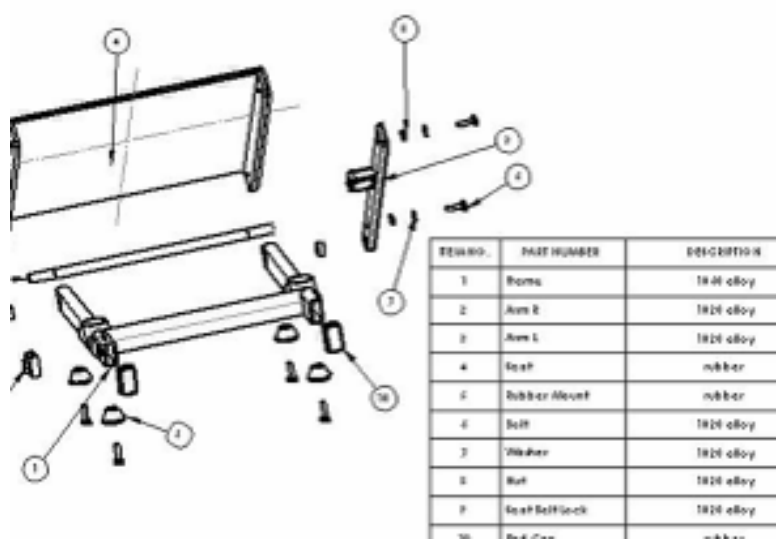

Figure 9. Exploded view and the BOM of a spring loaded chair seat.

Detailed design is aided by design analysis using the Finite Element Analysis (FEA) to ensure the adequate structural performance of the product (figure $10)$.

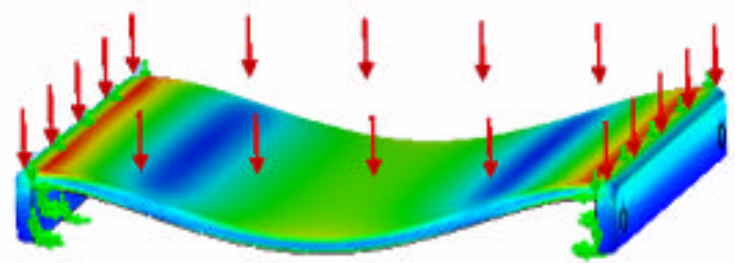

Figure 10. Stresses in the seat calculated determined using FEA.

Other design teams used different simulation tools like Motion Analysis or Flow Analysis depending on the needs and the nature of their design project.

Having completed detailed design and analysis the design team proceeds to evaluate their design using techniques such as Design for Manufacturing (DFM), Design for Assembly (DFA) (figure 11) and Design Failure Modes and Effect Analysis (DFMA) (figure 12). 


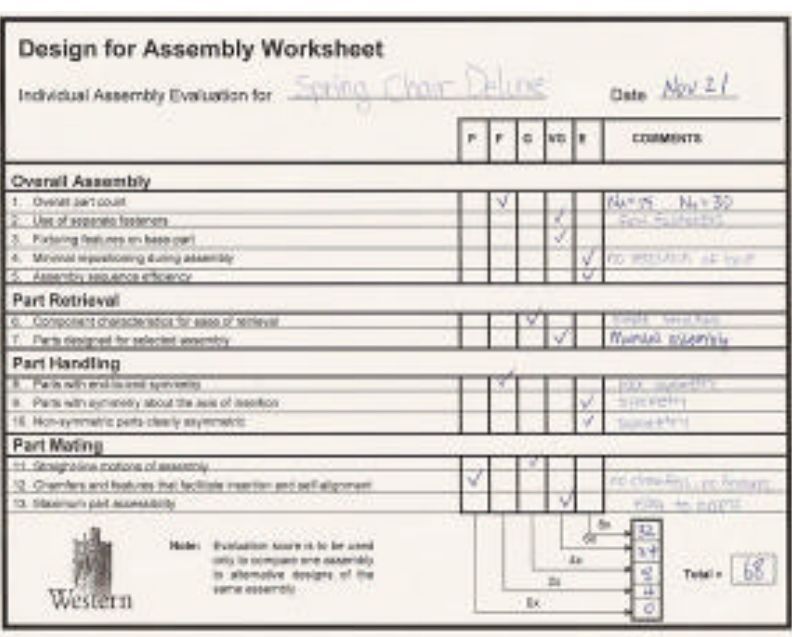

Figure 11. Design for Assembly worksheet used to evaluate the product for the ease of assembly.

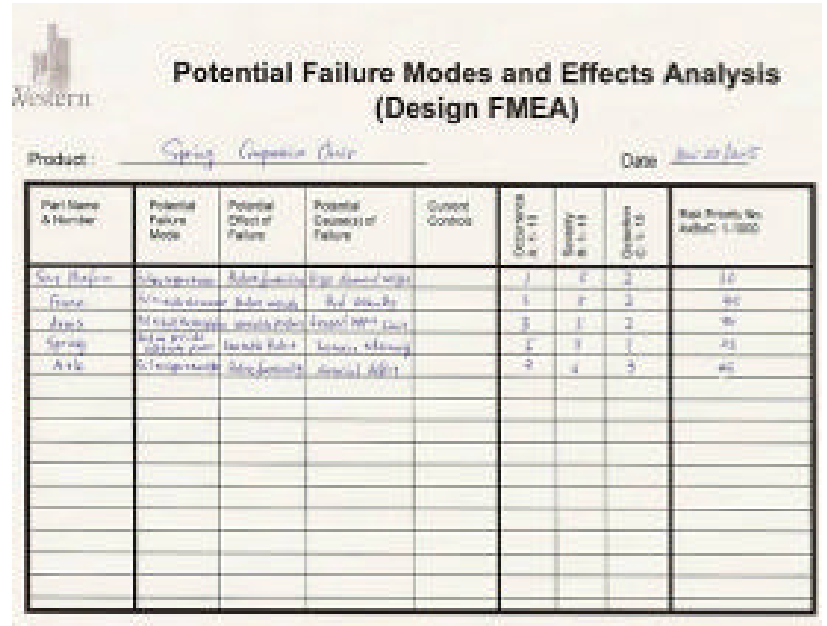

Figure 12. Design FMEA used to prioritize the risk of different failure modes.

The use of DFA and DFM in product design allows students to consider manufacturing and assembly issues which could not have been illustrated by prototype serving only to demonstrate essential principles of the design. The entire project is accompanied by cost analysis and is managed using Gantt charts and Critical Path Method (CPM). It also includes design considerations for recycle ability and disassembly upon the end of the useful life.

Finally the team constructs a physical prototype for testing key features for function and performance (figure 13). This completes the design process.

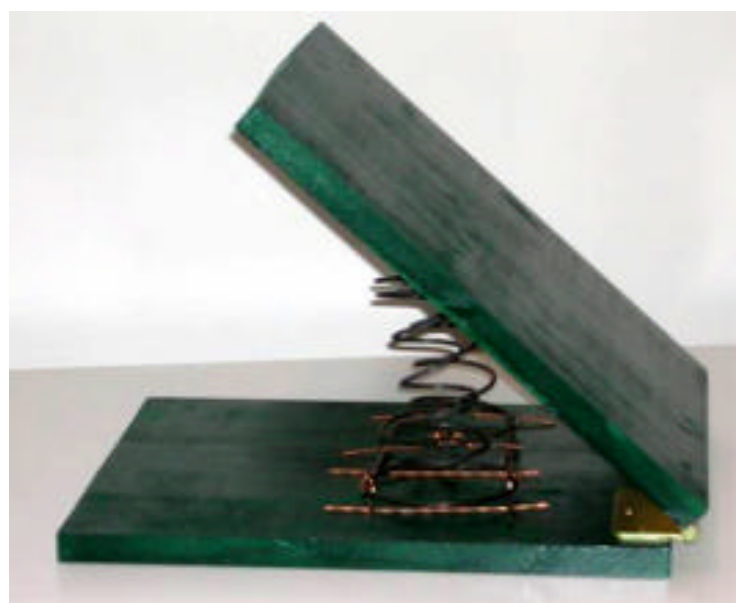
Figure 13. Photograph of the spring loaded
chair seat prototype.

\section{Use of CAE tools in the design process}

The use of simulation tools like FEA and Motion Analysis in the design project enables the instructors to incorporate the traditional design approach of creating prototypes (figure 14). In contrast Simulation Aided Design Process occurs when design iterations are performed on numerical models and prototype is used only for design validation rather than as a design tool (figure 15).

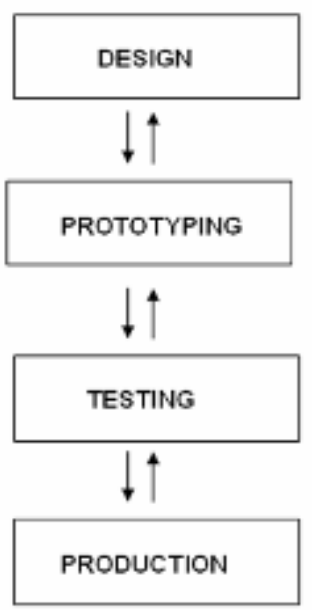

Figure 14. Traditional approach to design where multiple prototypes are created. 


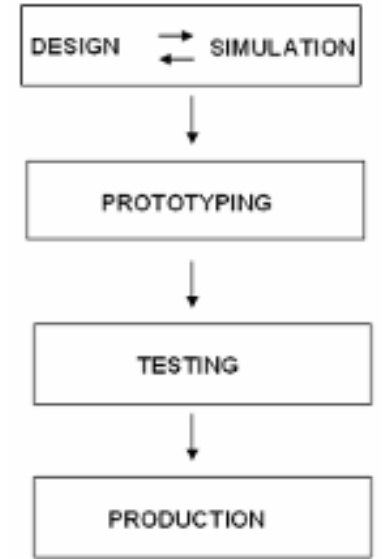

\section{Figure 15. Simulation driven design process where the prototype is NOT used as a design tool but only for design validation.}

\section{Conclusions}

The most important outcome of the course is not that students have learned and applied in design practice so many different methods and tools used in the design process. Neither it is the fact that they have designed something potentially useful.

The most important outcome of completing the Product Design and Development course is the realization that structured methods, established guidelines, and formal techniques exist that will help practicing engineers develop high-quality products. Not every technique discussed in the class is applicable to each design problem encountered in industry.

Many of the techniques become redundant with extensive practical experience. However, design engineers are always faced with new challenges demanding viable, cost effective solutions. These tools provide the sophisticated practitioner with guidance through the process and the means to communicate to the client or customer that the proposed solution works as it should if properly constructed and implemented. The techniques also force the design to address key issues related to form, functionality, safety, manufacturability, serviceability, reliability, cost, and environmental impact throughout the product lifecycle.

\section{References}

[1] Bralla, J.G., Design for Excellence. New York: McGraw-Hill, 1996.

[2] Bralla, J.G., Handbook of Product Design for Manufacturing. New York: McGraw-Hill, 1986.

[3] Boothroyd, G., Dewhurst, P., and Knight, W., Product Design for Manufacture and Assembly. New York: Marcel Dekker, 1994.

[4] Buhl, H.A., Creative Engineering Design. Ames Iowa: The University of Iowa Press, 1968.

[5] Cross, N., Engineering Design Methods: Strategies for Product Design. New York NY: John Wiley \& Sons, 2001.

[6] Dieter, G.E., Engineering Design: A Materials and Processing Approach. New York: McGraw-Hill, 1991

[7] Lindbeck, J.R., Product Design and Manufacture. Englewood Cliffs, N.J.: Prentice Hall, 1995.

[8] Otto, K.N. and Wood, K.L. Product Design: Techniques in Reverse Engineering and New Product Development. Upper Saddle River, N.J.: Prentice Hall, 2001.

[9] Pahl, G. and Beitz, W., Engineering Design: A Systematic Approach. London: Springer-Verlag, 1996.

[10] Redford, A. and Chal, J., Design for Assembly. London: McGraw-Hill, 1994.

[11] Ullman, D.G., The Mechanical Design Process. New York: McGraw-Hill, 1992.

[12] Ulrich, K.T. and Eppinger, SD., Product Design and Development (Third Edition). New York: McGraw-Hill, 2004. 